\title{
Relative cerebral hyperperfusion during cardiopulmonary bypass is associated with risk for postoperative delirium: a cross- sectional cohort study
}

\author{
Marcus Thudium¹, Richard K. Ellerkmann², Ingo Heinze ${ }^{1}$ and Tobias Hilbert ${ }^{1 *}$ (D)
}

\begin{abstract}
Background: Our objective was to evaluate if changes in on-pump cerebral blood flow, relative to the pre-bypass baseline, are associated with the risk for postoperative delirium (POD) following cardiac surgery.

Methods: In 47 consecutive adult patients, right middle cerebral artery blood flow velocity (MCAV) was assessed using transcranial Doppler sonography. Individual values, measured during cardiopulmonary bypass (CPB), were normalized to the pre-bypass baseline value and termed $M C A V_{\text {rel }}$. An MCAV rel $>100 \%$ was defined as cerebral hyperperfusion. Prevalence of POD was assessed using the Confusion Assessment Method for the Intensive Care Unit.

Results: Overall prevalence of POD was $27 \%$. In the subgroup without POD, 32\% of patients had experienced relative cerebral hyperperfusion during CPB, compared to 67\% in the subgroup with POD $(p<0.05)$. The mean averaged $M_{C A V}$ rel was $90( \pm 21) \%$ in the no-POD group vs. $112( \pm 32) \%$ in the POD group $(p<0.05)$, and patients developing delirium experienced cerebral hyperperfusion during CPB for about $39( \pm 35)$ min, compared to $6( \pm 11)$ min in the group without POD $(p<0.001)$. In a subcohort with pre-bypass baseline MCAV (MCAV bas) below the median MCAV bas of the whole cohort, prevalence of POD was $17 \%$ when $M C_{\text {rel }}$ during CPB was kept below $100 \%$, but increased to 53\% when these patients actually experienced relative cerebral hyperperfusion.

Conclusions: Our results suggest a critical role for cerebral hyperperfusion in the pathogenesis of POD following onpump open-heart surgery, recommending a more individualized hemodynamic management, especially in the population at risk.
\end{abstract}

Keywords: Cerebral blood flow, Delirium, Cardiac surgery, Cardiopulmonary bypass, Transcranial Doppler sonography

\section{Background}

An ageing population with increasing prevalence of cardiovascular diseases results in an increased caseload of cardiac surgery as well. Postoperative delirium (POD) is one major complication following cardiac surgery. It is known to increase length of intensive care unit (ICU) and hospital stay and postoperative mortality, thus representing a significant problem for the health care system [1]. Its pathophysiology, albeit still remaining elusive, is multifactorial [2].

\footnotetext{
* Correspondence: thilbert@uni-bonn.de

${ }^{1}$ Department of Anesthesiology and Intensive Care Medicine, University

Hospital Bonn, Sigmund-Freud-Strasse 25, 53127 Bonn, Germany

Full list of author information is available at the end of the article
}

Although POD is usually supposed to be associated with intraoperative periods of hypotension, there is some evidence suggesting the significance of sustained cerebral hyperperfusion during cardiopulmonary bypass (CPB) [3]. In a recent work, Hori et al. demonstrated the association of an arterial blood pressure above the upper limit of cerebral autoregulation with POD, suggesting cerebral hyperperfusion to be present in these patients [4].

Superior to blood pressure monitoring, transcranial Doppler sonography (TCD) offers the possibility to directly assess blood flow velocity in the middle cerebral artery (MCA), which is an indirect measurement of cerebral blood flow (CBF) [5]. We hypothesized that changes

(C) The Author(s). 2019 Open Access This article is distributed under the terms of the Creative Commons Attribution 4.0 International License (http://creativecommons.org/licenses/by/4.0/), which permits unrestricted use, distribution, and 
in on-pump CBF, relative to the pre-bypass baseline value, both measured by TCD, are associated with the prevalence of postoperative delirium. Our results may underline the importance of a more individualized hemodynamic management during cardiac surgery.

\section{Methods}

Aim was to evaluate if changes in on-pump cerebral blood flow, relative to the pre-bypass baseline, are associated with the risk for POD following cardiac surgery. This cross-sectional cohort study was conducted in accordance with the Declaration of Helsinki and after approval by the institutional review board of the University of Bonn (protocol number 300/16, date of approval 2016-06-16). According to the approval and due to the observational design of the study, informed consent was waived. Inclusion criteria were: patient age $>18$ years and elective on-pump open heart surgery. The exclusion criteria were as follows: emergency procedure, aortic arch surgery with circulatory arrest, pregnancy, and absence of a proper acoustic window. All patients received anesthesia induction according to standard procedures including arterial line, intubation, central venous catheterization, and urinary catheter. Anesthesia was induced with sufentanil, etomidate, and rocuronium and was maintained with sevoflurane and continuous infusion of sufentanil. The patients received noradrenaline as vasopressor and dobutamine for inotropic support (the latter not during $\mathrm{CPB}$ ). Median sternotomy was performed in apnea. After systemic heparinization and cannulation of the ascending aorta and of the right atrium or the superior and inferior vena cava, respectively, $\mathrm{CPB}$ was established using a roller pump (Advanced Perfusion System 1, Terumo Corporation, Tokyo, Japan) and a membrane oxygenator (Quadrox-I Adult, Maquet Getinge Group, Rastatt, Germany). The heart-lung machine (HLM) system was primed with $1,200 \mathrm{ml}$ of crystalloid infusion solution and 10,000 IU of heparin. After full HLM support was installed with a pump flow rate of $2.5 \mathrm{l} / \mathrm{m}^{2}$ body surface area*min, ventricular fibrillation was induced, and cardiac arrest was achieved by administering Calafiore warm blood or Bretschneider cardioplegia infusion. The aorta was then cross-clamped. Mild hypothermia $\left(32-34^{\circ} \mathrm{C}\right)$ was induced, and acid-base management was performed according to $\mathrm{pH}$-stat regimen. Towards the end of the surgical procedure, patients were rewarmed and subsequently weaned from the $\mathrm{CPB}$ after de-clamping of the aorta and sufficient reperfusion. After successful weaning from the $\mathrm{CPB}$, heparin was antagonized with protamine in an $80-100 \%$ dose of the initially administered heparin. All patients were transferred to ICU for postoperative care.

All patients received monitoring of bispectral index (BIS; BIS vista, Medtronic Minimally Invasive Therapies, Minneapolis, USA). Baseline TCD measurement of the right MCA was performed after anesthesia induction and before establishing CPB. A S5-1 transducer on a CX30 ultrasound system (Philips Medical Systems, Hamburg, Germany) was used. Measurements were performed via a temporal window, as it was previously described by Aaslid et al. (see Additional file 1: Figure S1, Supplemental Digital Content) [5]. First, the intracranial cavity was visualized in B-mode with a depth of $15 \mathrm{~cm}$, then depth was reduced to about $8 \mathrm{~cm}$. Color Doppler imaging was added, and the right MCA and the Circle of Willis were visualized. Once an appropriate angle was achieved, pulsed-wave Doppler was added on the M1 segment of the MCA in a depth between 4.5 and $5.5 \mathrm{~cm}$, and averaged blood flow velocity in MCA (MCAV) was measured. After aortic cross-clamping, MCAV was monitored every $10 \mathrm{~min}$ during $\mathrm{CPB}$, and these time points were named T1, T2, T3. etc. Additional simultaneous data collection included: mean arterial blood pressure (MAP), HLM pump flow, noradrenaline infusion rate, arterial $\mathrm{CO}_{2}$ partial pressure $\left(\mathrm{PaCO}_{2}\right)$, and body temperature.

Static cerebral autoregulation during $\mathrm{CPB}$ was assessed as follows: percentage changes of MAP and MCAV in relation to the corresponding preceding values were computed for each ten-minute assessment, and an autoregulatory index (AI) was calculated as pressure-flow velocity relationship $(\mathrm{AI}=\mathrm{MCAV}[\%$ change $] / \mathrm{MAP}[\%$ change]), similar to what was described by Zazulia et al., who used CBF instead of MCAV [6]. An AI that approximates 0 would indicate intact cerebral autoregulation. Time points where MAP changes were $<20 \%$ or where $\mathrm{PaCO}_{2}$ changed by an arbitrarily chosen cutoff value of more than $20 \%$ were excluded from calculation of AI to ensure validity [7].

Prevalence of postoperative delirium was assessed in extubated patients on the ICU using the CAM-ICU test (Confusion Assessment Method for the Intensive Care Unit). A german version of the assessment that has been validated for ventilated as well as extubated patients following cardiac surgery has been used [8]. Its components are described in detail elsewhere [9]. The CAM-ICU was performed twice every day by the same investigator that was blinded for the TCD data to exclude any observational bias. According to the criteria, patients were rated as having developed POD if they were CAM-ICU positive for at least one single examination within $48 \mathrm{~h}$ after extubation (i.e., in the immediate postoperative period, see also Evered et al. [10]). Patients were followed up with the Richmond Agitation Sedation Scale (RASS) to assess acute onset or fluctuation of mental status changes [11]. POD was diagnosed by the occurrence of inattention in combination with either an altered level of consciousness or disorganized thinking [9]. 
Based on data on the known prevalence of POD in cardiac surgery patients, it was planned to include at least 45 patients into the observation [12]. All data were transferred into MS Excel (Microsoft Corp., Redmond, USA). Statistical analysis and visualization was performed using IBM SPSS 24 (Armonk, NY, USA) and GraphPad PRISM 5 (La Jolla, CA, USA). Data are presented as mean values with standard deviation (SD) and minimum and maximum value, respectively. Outliers were identified using the method propagated by Leys et al. (absolute deviation around the median), whereby a threshold of 2.5 was used as rejection criterion [13]. Significance of intergroup differences was tested using unpaired, two-tailed Student's t-test. For categorical data, Fisher's exact test was used. The Pearson product-moment correlation coefficient was calculated to assess the association between the patients' age and their baseline MCAV. $P$ values $<0.05$ were considered statistically significant. The datasets generated and analyzed during the current study are available from the corresponding author on reasonable request.

\section{Results}

Between July 2016 and July 2017, a total of 47 consecutive patients were recruited to participate in the study. 3 patients were excluded from subsequent data analysis because of postoperative need for extracorporeal lung or cardiac support, respectively. Prevalence of POD in the whole cohort was 27\% (12 patients). Except for one individual in the no-POD group with a history of alcoholism, no patient suffered from chronic alcohol or drug abuse. No patient showed preexisting clinically relevant cognitive impairment or dementia, and prevalence of chronic arterial hypertension was equally distributed. Table 1 gives an overview of the basic patients' and the intraoperative details. Mean patients' age in the whole cohort was $69( \pm 9.8)$ years. Patients that developed POD were significantly older than those without delirium. Other recorded variables (gender, weight, height, body surface area, body mass index, duration of surgery as well as of aortic cross-clamping, baseline MAP, absolute MAP during $\mathrm{CPB}$, MAP relative to baseline during $\mathrm{CPB}$, HLM pump flow, noradrenaline infusion rate, and arterial $\mathrm{CO}_{2}$ partial pressure) showed no significant

Table 1 Patient and intraoperative details

\begin{tabular}{|c|c|c|c|}
\hline Parameter & no delirium & delirium & $p$ value \\
\hline Prevalence (n) & $32\left(73 \%{ }^{a}\right)$ & $12\left(27 \%{ }^{a}\right)$ & \\
\hline Age (years) & $67(10)$ & $75(5)$ & 0.008 \\
\hline Male gender ( $n$ ) & $23(72 \%)$ & $10(83 \%)$ & $0.7^{\mathrm{b}}$ \\
\hline Weight (kg) & $80(14)$ & $81(19)$ & 0.94 \\
\hline Height (cm) & $174(10)$ & $171(9)$ & 0.29 \\
\hline Body surface area $\left(\mathrm{m}^{2}\right)$ & $1.97(0.2)$ & $1.95(0.25)$ & 0.78 \\
\hline Body mass index $\left(\mathrm{kg} / \mathrm{m}^{2}\right)$ & $26.4(3.8)$ & $27.5(5.7)$ & 0.45 \\
\hline Chronic arterial hypertension ( $\mathrm{n}$ ) & $24(75 \%)$ & $10(83 \%)$ & $0.7^{b}$ \\
\hline \multicolumn{4}{|l|}{ Intraoperative details } \\
\hline Duration of aortic cross-clamping (min) & $91.3(37.8)$ & $97.6(35.6)$ & 0.66 \\
\hline Duration of surgery (min) & $275.0(71.6)$ & $288.3(57.3)$ & 0.57 \\
\hline Hematocrit preop. (\%) & $41.0(3.8)$ & $41.8(3.8)$ & 0.50 \\
\hline Hematocrit postop. (\%) & $30.5(4.0)$ & $30.7(2.5)$ & 0.88 \\
\hline Delta hematocrit (\%) & $10.5(4.7)$ & $11.2(3.9)$ & 0.66 \\
\hline BIS & $41.4(5.1)$ & $43.5(4.9)$ & 0.23 \\
\hline $\mathrm{MAP}_{\text {bas }}(\mathrm{mmHg})$ & $63(8.4)$ & $69(15.1)$ & 0.11 \\
\hline $\mathrm{MAP}_{\text {abs }}(\mathrm{mmHg})$ & $61(6.7)$ & $64(5.8)$ & 0.19 \\
\hline MAP rel $(\%)$ & $98(16.1)$ & $96(21.9)$ & 0.75 \\
\hline HLM pump flow $\left(1 / \mathrm{min}^{*} \mathrm{~m}^{2}\right)$ & $2.4(0.29)$ & $2.3(0.37)$ & 0.30 \\
\hline Noradrenaline ( $\mu \mathrm{g} / \mathrm{min}$ *kg) & $0.11(0.09)$ & $0.11(0.11)$ & 0.96 \\
\hline $\mathrm{PaCO}_{2}(\mathrm{mmHg})$ & $36.2(3.7)$ & $35.4(4.1)$ & 0.56 \\
\hline Temperature $\left({ }^{\circ} \mathrm{C}\right)$ & $34.5(1.1)$ & $34(1.0)$ & 0.05 \\
\hline
\end{tabular}

Values are given as mean $( \pm S D)$ of the averaged individual values

$\mathrm{MAP}=$ mean arterial blood pressure, $\mathrm{HLM}=$ heart-lung machine, $\mathrm{BIS}=$ bispectral index

${ }^{a}$ percentage of whole cohort, ${ }^{b}$ Fisher's exact test 
differences between the two subgroups. BIS values ranged from 30 to 55 in both subcohorts with no intergroup differences. Hematocrit was significantly decreased postoperatively compared to the preoperative values (30.5 (3.7) \% vs. 41.2 (3.8) \%, $p<0.0001$ (paired, two-tailed Student's t-test)), however, neither pre- nor postoperative values nor their delta differed between no-POD and POD cohort.

Blood flow velocity in the right MCA was measured using TCD (Additional file 1: Figure S1, Supplemental Digital Content). Individual values, assessed during HLM time every $10 \mathrm{~min}$, were normalized to the baseline value obtained before cannulation of the aorta and termed $M C A V_{\text {rel }}$. Cerebral hyperperfusion was defined as $\mathrm{MCAV}_{\text {rel }}>100 \%$. Percentage amount of patients that experienced cerebral hyperperfusion during $\mathrm{CPB}$ was $32 \%$ in the subgroup without, but was $67 \%$ in the subgroup with POD, revealing a significant difference ( $p$ $=0.04)$. The mean averaged $M C A V_{\text {rel }}$ likewise differed, as it was $90( \pm 21) \%$ in the no-POD group vs. $112( \pm 32)$ $\%$ in the POD group $(p=0.01)$ (Fig. 1a). In contrast, there was no significant difference regarding the mean absolute MCAV during CPB ( 41.3 vs. $37.1 \mathrm{~cm} / \mathrm{s}$ ). Neither in the whole cohort nor in any of the subcohorts, relative changes of hematocrit correlated with the relatively changing MCAV (Pearson $r$ for $M C A V_{\text {rel }}$ vs. delta hematocrit: whole cohort: $\mathrm{r}=-0.03, p=0.83$; no-POD: $\mathrm{r}$ $=0.1, p=0.59$; POD: $\mathrm{r}=-0.42, p=0.18$ ).

The duration of cerebral hyperperfusion was highly significantly related to the development of POD: in the subgroup that developed postoperative delirium, patients experienced cerebral hyperperfusion for about $39( \pm 35)$ min, compared to $6( \pm 11) \mathrm{min}$ in the group without postoperative delirium $(p<0.001)$ (Fig. 1b). Normalized to the total HLM time, in the POD group, the mean percentage time of cerebral hyperperfusion was $58( \pm 41)$ $\%$, whereas in the no-POD group, it was $9( \pm 22) \%(p<$ $0.0001)$. Figure 2 visualizes the relative cerebral blood flow velocities during $\mathrm{CPB}$ together with the corresponding MAP values from two representative patients over the time. MAP was kept within a range between 50 and $90 \mathrm{mmHg}$ almost all the time in both patients. However, the MCAV of patient no. 26, developing POD, was above his baseline at any time point, with peak values exceeding $160 \%$. By contrast, MCAV of patient no. 27, which developed no delirium, was below his individual baseline value almost the whole time during $\mathrm{CPB}$. Neither of them showed a correlation between MAP and relative MCAV (not shown).

Cerebral autoregulatory index (AI) values are given in Table 2. Overall AI in the whole cohort was 0.18 , and there was no significant difference between the indices in no-POD and POD group. It has been shown that the cerebral autoregulatory capacity might be different for decreasing and increasing blood pressure [7]. In our cohort, AI calculated for decreasing MAP did not differ from that calculated for an increase in MAP $(p=0.97)$ when stable $\mathrm{PaCO}_{2}$ conditions have been respected. This also accounted for either subgroup.

Since not absolute but relative cerebral blood flow velocities during $\mathrm{CPB}$ differed between the two subgroups, we compared the patients' baseline MCAV values, assessed before beginning of $\mathrm{CPB}$ and used as reference. Mean $M C A V_{\text {bas }}$ was significantly lower in
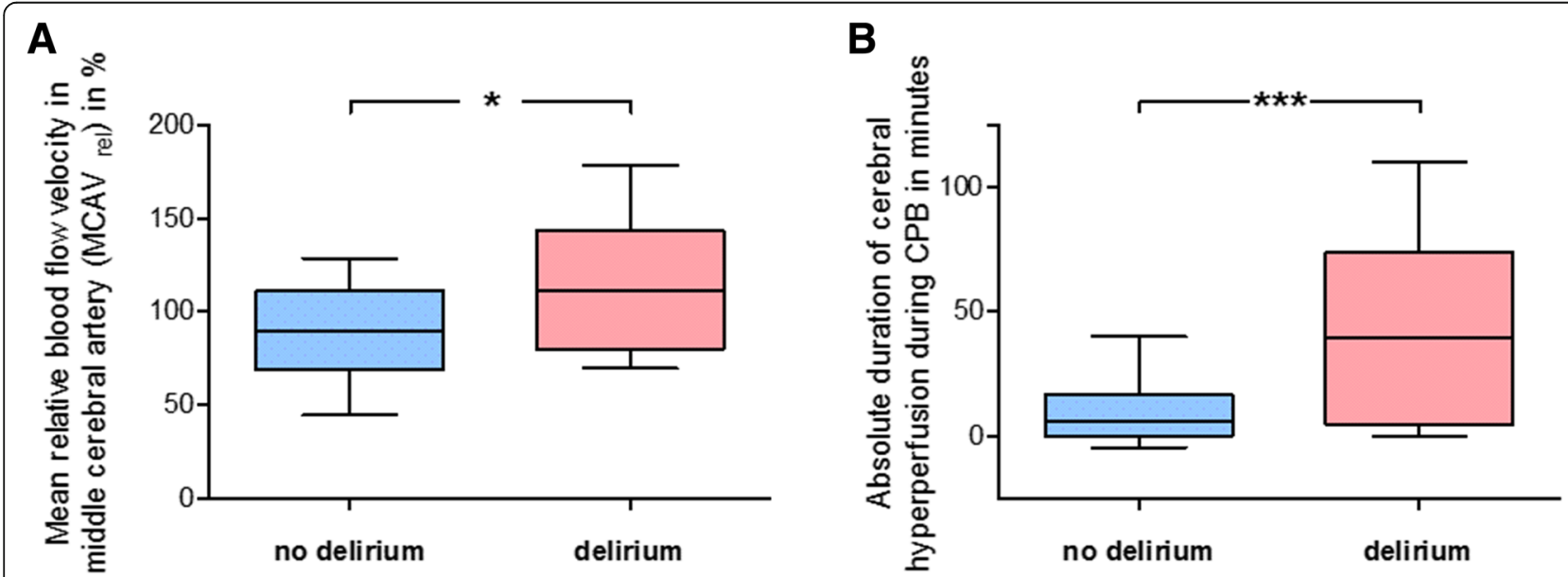

Fig. 1 Relative blood flow velocity in middle cerebral artery during cardiopulmonary bypass. Blood flow velocity in the right middle cerebral artery (MCAV) was measured using transcranial Doppler sonography. Individual values, assessed during cardiopulmonary bypass (CPB) every 10 min, were normalized to the baseline value obtained before cannulation of the aorta and was termed $M_{C} \mathrm{AV}_{\text {rel }}$. Cerebral hyperperfusion was defined as relative MCAV > 100\%. a Mean averaged MCAV rel values for the no-POD group and the POD group, respectively. $\mathbf{b}$ Duration of cerebral hyperperfusion periods during CPB in the no-POD group and the POD group, respectively.Mean \pm SD (boxes) and minimum and maximum (whiskers); $n=32$ (no delirium) and $n=12$ (delirium); unpaired, two-tailed Student's t-test (b); ${ }^{*} p<0.05,{ }^{* * *} p<0.005$ 


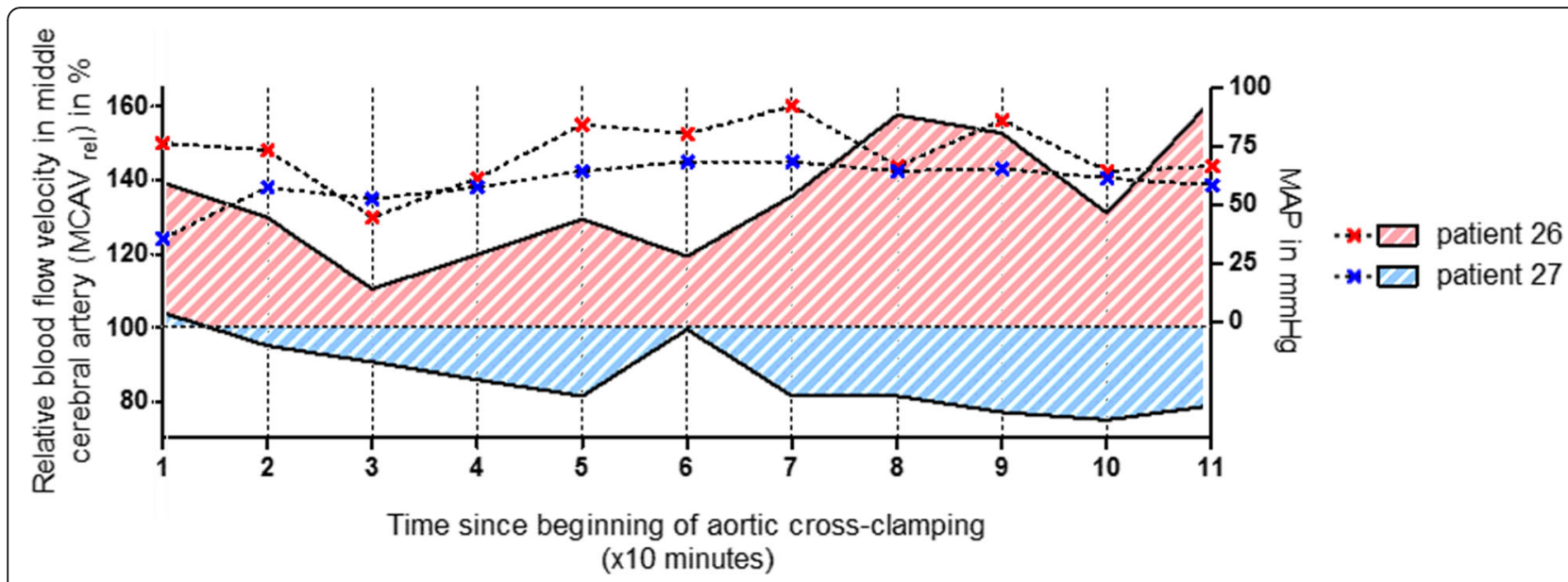

Fig. 2 Individual relative blood flow velocities in middle cerebral artery during cardiopulmonary bypass. Blood flow velocity in the right middle cerebral artery (MCAV) was measured using transcranial Doppler sonography. Individual values, assessed during cardiopulmonary bypass (CPB) every $10 \mathrm{~min}$, were normalized to the baseline value obtained before cannulation of the aorta and was termed $M C A V_{\text {rel }}$. The figure shows the relative cerebral blood flow velocities in right MCA during CPB (solid lines, plotted on left $Y$ axis), together with the corresponding mean arterial blood pressure (MAP) values (dashed lines, plotted on right $Y$ axis), from two representative patients over the time. MCAV of patient no. 27, which developed no delirium, was below his individual baseline value almost the whole time during CPB. By contrast, the MCAV of patient no. 26, developing POD, was above his baseline at any time point, with peak values exceeding $160 \%$. Note that MAP was kept within a range between 50 and $90 \mathrm{mmHg}$ almost all the time in both patients

patients that developed postoperative delirium (32.4 $( \pm 12.0) \mathrm{cm} / \mathrm{s})$ than in those without POD $(46.1( \pm 11.9)$ $\mathrm{cm} / \mathrm{s} ; p=0.002$ ) (Fig. 3a). As there was also a difference in the patients' age (Table 1), we found a significant correlation between age and $M C A V_{\text {bas }}$, with elderly patients having a reduced baseline blood flow velocity $(r=-0.6$, $p<0.0001$ ) (Fig. 3b). We then divided the whole cohort using the median baseline MCAV, which was $40.1 \mathrm{~cm} / \mathrm{s}$, to focus only on those patients with reduced basal CBF (i.e. with $\mathrm{MCAV}_{\text {bas }}<40.1 \mathrm{~cm} / \mathrm{s}$ ). This revealed 21 patients. Most of the POD patients (9 out of 12) belonged to this subcohort, but the majority ( 8 out of those 9 patients) was actually exposed to hyperperfusion during $\mathrm{CPB}$, while only one had $\mathrm{MVAC}_{\text {rel }}$ values below $100 \%$. In other words, prevalence of POD in the subcohort was $17 \%$, when relative MCAV during $\mathrm{CPB}$ was kept below $100 \%$, but it markedly increased to $53 \%$ when these patients experienced relative cerebral hyperperfusion during $\mathrm{CPB}$, suggesting that not reduced basal $\mathrm{CBF}$ alone but too high $\mathrm{MCAV}_{\text {rel }}$ (i.e. cerebral hyperperfusion) promotes postoperative delirium.

Table 2 Cerebral autoregulatory index (Al)

\begin{tabular}{lllll}
\hline Parameter & whole cohort & no delirium & delirium & $p$ value \\
\hline $\mathrm{Al}$ & $0.18(0.44)$ & $0.19(0.39)$ & $0.17(0.58)$ & 0.92 \\
$\mathrm{Al}_{\mathrm{dcr}}$ & $0.18(0.44)$ & $0.16(0.48)$ & $0.25(0.36)$ & 0.63 \\
$\mathrm{Al}_{\text {incr }}$ & $0.18(0.59)$ & $0.21(0.39)$ & $0.1(0.9)$ & 0.66 \\
\hline
\end{tabular}

Values are given as mean $( \pm$ SD) of the averaged individual values. $P$ value is given for unpaired, two-tailed Student's t-test comparing no delirium and delirium group

$\mathrm{Al}=$ autoregulatory index, $\mathrm{Al}_{\mathrm{dcr} / \text { incr }}=$ autoregulatory index for decreasing/increasing MAP

\section{Discussion}

$\mathrm{CPB}$ during cardiac surgery has been demonstrated to cause alterations of the cerebral blood flow [14]. The main objective of this study was to evaluate if such changes in brain perfusion, as assessed by TCD, are related to the development of postoperative delirium, being one of the most frequent neuropsychologic complications in cardiac surgery. Our analyses revealed that patients with a reduced baseline MCAV, measured before $\mathrm{CPB}$, are prone to experience relative cerebral hyperperfusion during $\mathrm{CPB}$, when pump flow of the HLM is adjusted according to body weight and height. These patients demonstrated a significantly higher prevalence of delirium during the early postoperative period.

In the healthy adult brain, under physiological and normal intracranial pressure conditions, CBF is maintained constant over a definite range of perfusion pressure, i.e. systemic blood pressure. This phenomenon, termed cerebral autoregulation (CAR), ensures a CBF of about $50 \mathrm{ml}$ per $100 \mathrm{~g}$ of brain tissue per minute, given that perfusion pressure is within a range of 60 to 160 $\mathrm{mmHg}$ [15]. During mild hypothermia for cardiac surgery, it is accepted that autoregulation is preserved [16]. In our study, overall static AI was 0.18 for the whole cohort, with no significant differences between the two groups, suggesting intact CAR in our patients. Hypothermia was very mild, as the mean body temperature was around $34^{\circ} \mathrm{C}$ in both subgroups. Furthermore, $\mathrm{PaCO}_{2}$ values did not differ among no-POD and POD patients. 

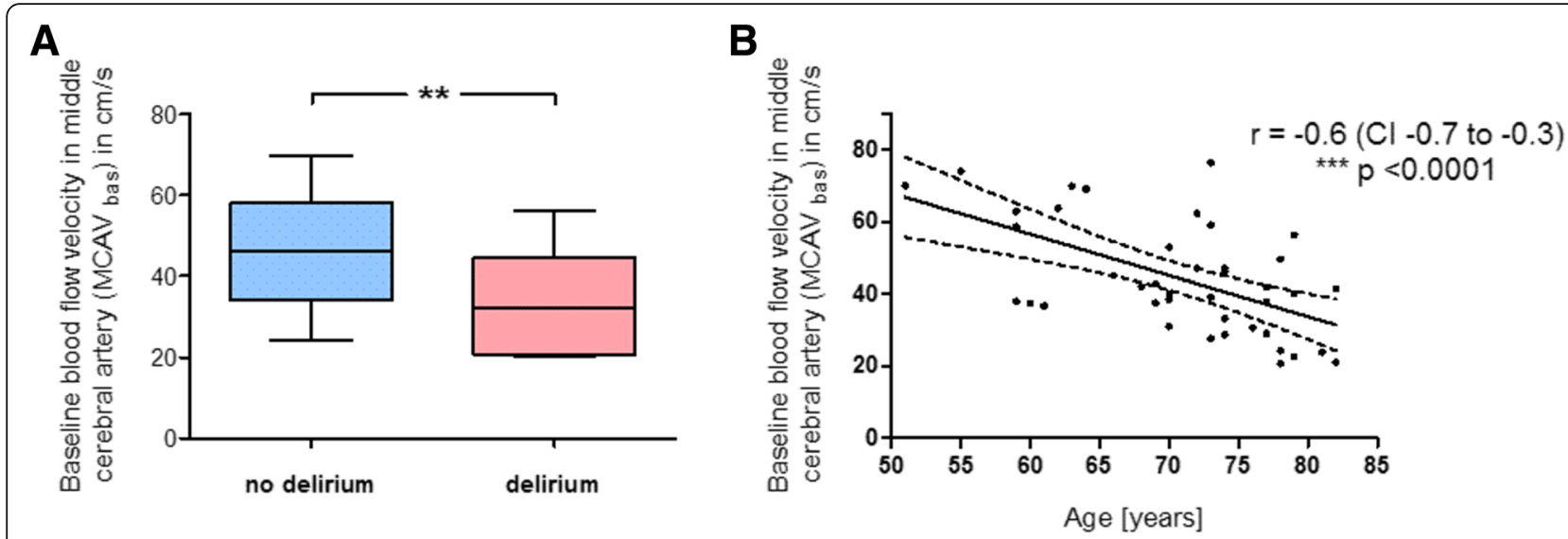

Fig. 3 Significance of age and baseline blood flow velocity in middle cerebral artery for cerebral hyperperfusion during cardiopulmonary bypass. Blood flow velocity in the right middle cerebral artery (MCAV) was measured using transcranial Doppler sonography before cardiopulmonary bypass (CPB) and was termed MCAV bas. a Comparison of the patients' baseline MCAV values (in $\mathrm{cm} / \mathrm{s}$ ), assessed before beginning of CPB, between the no-POD group and the POD group. $\mathbf{b}$ Association of the patients' age with their measured $M C A V_{\text {bas }}$ values, with elderly patients having a reduced baseline blood flow velocity (Pearson product-moment correlation). The dashed curved lines indicate the confidence band. $r=$ Pearson product-moment correlation coefficient, $\mathrm{Cl}=$ confidence interval; mean $\pm \mathrm{SD}$ (boxes) and minimum and maximum (whiskers); $\mathrm{n}=32$ (no delirium) and $\mathrm{n}=12$ (delirium); unpaired, two-tailed Student's t-test (a); ${ }^{* *} p<0.01,{ }^{* *} p<0.005$

Delirium is one cardinal complication in cardiac surgery, significantly influencing the patients' outcome [1]. Often occurring during the early postoperative period, it accounts for prolonged lengths of ICU and hospital stay. A number of risk factors have been identified, however, the detailed underlying pathogenetic mechanisms are still elusive [2,17]. Although it is generally assumed that neurologic or neuropsychologic complications arise from insufficient cerebral perfusion (i.e. too low CBF), there is evidence for a critical role of cerebral hyperperfusion [15]. Patel et al. demonstrated a significant decline in late postoperative cognitive function in patients whose $\mathrm{CBF}$ during $\mathrm{CPB}$ was almost doubled compared to those that were clinically unremarkable [16]. Venn et al. could confirm these findings [18]. Cerebral hyperperfusion syndrome has originally been described as a result of therapeutic interventions on arterial vessels providing blood supply to the brain, e.g., following carotid endarterectomy (CEA) [19]. Usual symptoms include a triad of headache, seizure, and transient neurologic deficits. CT or MR imaging reveals, among others, a brain edema as pathophysiologic correlate [20]. Although rare, case reports give anecdotal reference to hyperperfusion syndrome following cardiac surgery, presenting with postoperative delirium [21]. In an animal model of selective cerebral perfusion, used during aortic surgery, Haldenwang et al. could demonstrate that high CBF, compared to a low-flow regimen, resulted in cerebral edema and increasing intracranial pressure [22]. Studies on septic, non-cardiac surgery patients revealed sepsis-induced disturbed CAR, likewise being associated with delirium and suggesting a role for hyperperfusion during episodes of critical surges of arterial blood pressure that overstress the autoregulative capacity of cerebral vessels [23-26].

We performed serial studies on cardiac surgery patients that revealed a significant association of the risk for postoperative delirium with increased mean $\mathrm{CBF}$ velocities, as assessed by TCD during $\mathrm{CPB}$, relative to the pre-bypass baseline. These increases were not limited to any specific phase of CPB. Prevalence of POD in our cohort was $27 \%$, being in accordance with recent review literature [12]. Our findings are in line with what is described by Hori et al., who used near-infrared spectroscopy (NIRS) to determine the upper limit of CAR [4]. Their analyses revealed that excursions of the MAP above this limit were significantly associated with an increased risk for postoperative delirium. According to calculation of AI, pressure CAR was intact in our patients, and MAP values during $\mathrm{CPB}$ did not differ between the two groups. However, we see intergroup differences in relative cerebral blood flow. This highlights the impact of HLM pump flow rate, which may affect cerebral perfusion completely independent of other CBF-regulating parameters such as systemic blood pressure [27].

In our patients, in contrast to the relative CBF, absolute MCAV during CPB did not differ between POD and no-POD group. Therefore, basal MCAV, which was used as reference when calculating the relative hyperperfusion during $\mathrm{CPB}$, was significantly lower in patients that developed POD. The patients' age has consistently been identified as one well-documented independent risk factor for the development of POD in cardiac surgery $[2,28]$. Although cerebrovascular alterations or an increased incidence of neuropsychiatric disorders in the elderly patient 
likely play a pathogenetic role, specific underlying mechanisms for this relation have not yet been identified. Our analyses revealed a significant association between the patients' age and a reduced baseline MCAV, which is known from previous studies $[29,30]$. We defined cerebral hyperperfusion as relative MCAV > 100\%, normalized to the baseline, suggesting that age-related reduced basal MCAV is a source of hyperperfusion during CPB. However, if a low pre-bypass baseline MCAV actually increases the individual vulnerability to intraoperative hyperperfusion leading to subsequent delirium, or if it may be just a reflection of a reduced cerebral metabolism in the elderly patient that per se increases the risk for POD cannot be answered clearly by our results. We observed that the risk for POD was markedly increased particularly in those patients with reduced baseline MCAV that were actually hyperperfused during $\mathrm{CPB}$, compared to those without hyperperfusion periods. Furthermore, the cumulative duration of such hyperperfusion periods was associated with the development of delirium. This all gives rise to the assumption that CPB-induced hyperperfusion may reflect one possible mechanistic link between age and POD, when HLM pump flow is adjusted only according to the patient's body weight and height. But additional studies are urgently required, including prospective design and randomized interventional perfusion strategies (e.g., conservative CPB management vs. adjustment to continuously monitored $\mathrm{CBF}$ ), to determine the mechanistic role of age-related reduced MCAV for the development of POD following cardiac surgery and to clarify if prevention of relative cerebral hyperperfusion during $\mathrm{CPB}$ may reduce the risk for POD.

The relationship between $\mathrm{CBF}$ and TCD-derived MCAV remains one potential methodical limitation of our findings. Since Aaaslid et al. first described the use of TCD to assess CBF in 1982, numerous authors aimed to validate this method for various clinical situations, including CPB (see also Caldas et al. [31]). During mild hypothermic $\mathrm{CPB}$, results may be ambiguous, but it can be assumed that at least changes of flow velocity in the $\mathrm{MCA}$ reflect changes in $\mathrm{CBF}$ as long as arterial $\mathrm{CO}_{2}$ partial pressure and thus the diameter of the basal cerebral arteries remain constant [32, 33]. Therefore, assessing cerebral perfusion as well as pressure CAR during CPB using TCD appears to be valid. In addition, although the impact of usual dosages of volatile anesthetics on this relationship seems to be small, we intentionally determined baseline MCAV in anesthetized and not in awake patients prior to $\mathrm{CPB}$ to exclude an effect of anesthesia induction on TCD measurements [34].

Preoperative hematocrit values were significantly higher than those obtained postoperatively. Although its influence is rather small, compared to pump flow or systemic blood pressure, changing hematocrit may alter CBF $[35,36]$. If hemodilution affects the validity of TCD to evaluate $\mathrm{CBF}$ during $\mathrm{CPB}$ is still uncertain. While some authors showed that during deep hypothermic $\mathrm{CPB}, \mathrm{CBFV}$ increases with decreasing hematocrit [37], others have demonstrated that under conditions of laminar flow, the linear association between flow and velocity is not altered by changes in hematocrit in clinically relevant ranges [38]. Moreover, non-pulsatile flow during $\mathrm{CPB}$ itself may reduce the impact of hemodilution on CBFV [39]. Thus, the findings of Paut and Bissonnette "[...] support the use of transcranial Doppler sonography to estimate cerebral blood flow [...] during bypass." [38]. Furthermore, it has been shown that cerebral autoregulation is preserved even with decreasing hematocrit as long as $\mathrm{PaCO}_{2}$ is held within normal ranges [40]. In our patients, pre- as well as postoperative hematocrit values in the POD group equaled those in the no-POD group. Furthermore, neither in the whole cohort nor in any of the subcohorts, relative changes of hematocrit correlated with the relatively changing MCAV. Together with the observed association of subsequent POD not only with increased relative CBFV but also its duration, this makes a relevant effect of intraoperative hemodiluation on our findings highly unlikely.

In addition, other important possible confounders such as preexisting micronutrient deficiencies or clinically inconspicuous cognitive impairment cannot be ruled out with absolute certainty, as comprehensive preoperative tests (e.g., Nutritional Risk Screening (NRS), see also Ringaitiene et al. [41]) have not been performed. Furthermore, due to the short follow-up period of $48 \mathrm{~h}$ following extubation, we have no data on the possible development of postoperative cognitive dysfunction (POCD), which is said to occur weeks, months or even years after surgery, in contrast to POD, which is seen during the immediate postoperative period [10]. Further studies with extended follow-up are needed.

\section{Conclusions}

Taken together, our results suggest the necessity of a more individualized hemodynamic management during $\mathrm{CPB}$, especially in the population at risk. Systemic blood flow velocity significantly affects $\mathrm{CBF}$, independent of perfusion pressure. During CPB, HLM pump flow may be easily adapted, and we recommend integrating dynamic parameters such as measured patient's individual baseline CBF instead of using body surface area when adjusting pump flow rate. TCD can be a useful intraoperative guiding instrument for adequate hemodynamic parameters. 


\section{Additional file}

Additional file 1: Figure S1: Assessment of blood flow velocity in middle cerebral artery by transcranial Doppler sonography (A) Circle of Willis and position of the ultrasound probe for insonation of the right middle cerebral artery via a temporal window. (from: Wikimedia Commons. Image courtesy of Rune Aaslid (user name: Runeaaslid). The file is licensed under the Creative Commons Attribution 3.0 Unported license. Permission is granted to copy, distribute and/or modify under the terms of the GNU Free Documentation License, Version 1.2 or any later version.) (B) Color Doppler (upper window) and pulsed-wave Doppler sonography (lower window) of the M1 segment of the middle cerebral artery. Measured blood flow velocity was averaged over time (time-averaged peak velocity, TAPV). (TIF $4242 \mathrm{~kb}$ )

\section{Abbreviations}

Al: Autoregulatory index; BIS: Bispectral index; CAM-ICU: Confusion Assessment Method for the Intensive Care Unit; CAR: Cerebral autoregulation; CBF: Cerebral blood flow; CEA: Carotid endarterectomy; HLM: Heart-lung machine; ICU : Intensive care unit; MCA: Middle cerebral artery; MCAV: Blood flow velocity in MCA; NIRS: Near-infrared spectroscopy; $\mathrm{PaCO}_{2}$ : Arterial $\mathrm{CO}_{2}$ partial pressure; $\mathrm{POD}$ : Postoperative delirium; TCD: Transcranial Doppler sonography

\section{Acknowledgements}

Not applicable.

\section{Funding}

The authors declare that they received no funding from any external organization for the submitted work.

\section{Availability of data and materials}

The datasets used and/or analysed during the current study are available from the corresponding author on reasonable request.

\section{Authors' contributions}

MT and TH designed the study. MT, $\mathrm{H}$, and TH performed acquisition of clinical data. TH carried out data analysis. MT and TH prepared the manuscript and figures. RKE and $\mathrm{H}$ revised the manuscript critically for important intellectual content. RKE provided project leadership. All authors read and approved the final manuscript.

\section{Ethics approval and consent to participate}

This observation was performed after approval by the institutional review board of the University of Bonn (protocol number 300/16, date of approval 2016-06-16). According to the approval, informed consent was waived.

\section{Consent for publication}

Not applicable.

\section{Competing interests}

The authors declare that they have no competing interests.

\section{Publisher's Note}

Springer Nature remains neutral with regard to jurisdictional claims in published maps and institutional affiliations.

\footnotetext{
Author details

'Department of Anesthesiology and Intensive Care Medicine, University Hospital Bonn, Sigmund-Freud-Strasse 25, 53127 Bonn, Germany. ${ }^{2}$ Department of Anesthesiology and Intensive Care Medicine, Dortmund Hospital, Beurhausstrasse 40, 44137 Dortmund, Germany.
}

Received: 23 October 2018 Accepted: 25 February 2019 Published online: 09 March 2019

\section{References}

1. Mangusan RF, Hooper V, Denslow SA, Travis L. Outcomes associated with postoperative delirium after cardiac surgery. Am J Crit Care. 2015;24:156-63.
2. Zaal IJ, Devlin JW, Peelen LM, Slooter AJC. A systematic review of risk factors for delirium in the ICU. Crit Care Med. 2015:43:40-7.

3. Goto T, Maekawa K. Cerebral dysfunction after coronary artery bypass surgery. J Anesth. 2014;28:242-8.

4. Hori D, Brown C, Ono M, Rappold T, Sieber F, Gottschalk A, et al. Arterial pressure above the upper cerebral autoregulation limit during cardiopulmonary bypass is associated with postoperative delirium. Br J Anaesth. 2014;113:1009-17.

5. Aaslid R, Markwalder TM, Nornes H. Noninvasive transcranial Doppler ultrasound recording of flow velocity in basal cerebral arteries. J Neurosurg. 1982;57:769-74.

6. Zazulia AR, Videen TO, Morris JC, Powers WJ. Autoregulation of cerebral blood flow to changes in arterial pressure in mild Alzheimer's disease. J Cereb Blood Flow Metab. 2010;30:1883-9.

7. Numan T, Bain AR, Hoiland RL, Smirl JD, Lewis NC, Ainslie PN. Static autoregulation in humans: a review and reanalysis. Med Eng Phys. 2014;36:1487-95.

8. Klugkist M, Sedemund-Adib B, Schmidtke C, Schmucker P, Sievers HH, Hüppe M. Confusion assessment method for the intensive care unit (CAM-ICU). Anaesthesist. 2008;57:464-74.

9. Guenther U, Popp J, Koecher L, Muders T, Wrigge H, Ely EW, et al. Validity and reliability of the CAM-ICU flowsheet to diagnose delirium in surgical ICU patients. J Crit Care. 2010;25:144-51.

10. Evered L, Silbert B, Knopman DS, Scott DA, DeKosky ST, Rasmussen LS, et al. Recommendations for the nomenclature of cognitive change associated with Anaesthesia and surgery -2018. Anesthesiol J Am Soc Anesthesiol. 2018;129:872-9.

11. Ely EW, Truman B, Shintani A, Thomason JWW, Wheeler AP, Gordon S, et al. Monitoring sedation status over time in ICU patients: reliability and validity of the Richmond agitation-sedation scale (RASS). JAMA. 2003;289:2983-91

12. Crocker E, Beggs T, Hassan A, Denault A, Lamarche $Y$, Bagshaw S, et al. Long-term effects of postoperative delirium in patients undergoing cardiac operation: a systematic review. Ann Thorac Surg. 2016;102:1391-9.

13. Leys C, Ley C, Klein O, Bernard P, Licata L. Detecting outliers: do not use standard deviation around the mean, use absolute deviation around the median. J Exp Soc Psychol. 2013:49:764-6.

14. Henriksen L. Brain luxury perfusion during cardiopulmonary bypass in humans. A study of the cerebral blood flow response to changes in $\mathrm{CO}_{2}$, O2, and blood pressure. J Cereb Blood Flow Metab. 1986;6:366-78.

15. Phillips SJ, Whisnant JP. Hypertension and the brain. The National High Blood Pressure Education Program. Arch Intern Med. 1992;152:938-45.

16. Patel RL, Turtle MR, Chambers DJ, Newman S, Venn GE. Hyperperfusion and cerebral dysfunction. Effect of differing acid-base management during cardiopulmonary bypass. Eur J Cardio-Thorac Surg Off J Eur Assoc CardioThorac Surg. 1993;7:457-63 discussion 464.

17. Gosselt AN, Slooter AJ, Boere PR, Zaal IJ. Risk factors for delirium after onpump cardiac surgery: a systematic review. Crit Care. 2015;19. https://doi.org/10.1186/s13054-015-1060-0.

18. Venn GE, Patel RL, Chambers DJ. Cardiopulmonary bypass: perioperative cerebral blood flow and postoperative cognitive deficit. Ann Thorac Surg. 1995:59:1331-5.

19. Adhiyaman V, Alexander S. Cerebral hyperperfusion syndrome following carotid endarterectomy. QJM. 2007:100:239-44.

20. van Mook WNKA, Rennenberg RJMW, Schurink GW, van Oostenbrugge RJ, Mess WH, Hofman PAM, et al. Cerebral hyperperfusion syndrome. Lancet Neurol. 2005:4:877-88.

21. Ogasawara K, Komoribayashi N, Kobayashi M, Fukuda T, Inoue T, Yamadate K, et al. Neural damage caused by cerebral hyperperfusion after arterial bypass surgery in a patient with moyamoya disease: case report. Neurosurgery. 2005:56:E1380 discussion E1380.

22. Haldenwang PL, Strauch JT, Amann I, Klein T, Sterner-Kock A, Christ H, et al. Impact of pump flow rate during selective cerebral perfusion on cerebral hemodynamics and metabolism. Ann Thorac Surg. 2010;90:1975-84.

23. Pfister D, Siegemund M, Dell-Kuster S, Smielewski P, Rüegg S, Strebel SP, et al. Cerebral perfusion in sepsis-associated delirium. Crit Care Lond Engl. 2008;12:R63

24. Schramm P, Klein KU, Falkenberg L, Berres M, Closhen D, Werhahn KJ, et al. Impaired cerebrovascular autoregulation in patients with severe sepsis and sepsis-associated delirium. Crit Care Lond Engl. 2012;16:R181.

25. Berg RMG, Plovsing RR, Ronit A, Bailey DM, Holstein-Rathlou N-H, Møller K Disassociation of static and dynamic cerebral autoregulatory performance in 
healthy volunteers after lipopolysaccharide infusion and in patients with sepsis. Am J Physiol Regul Integr Comp Physiol. 2012;303:R1127-35.

26. Aggarwal M, Khan IA. Hypertensive crisis: hypertensive emergencies and urgencies. Cardiol Clin. 2006;24:135-46.

27. Moerman A, Denys W, De Somer F, Wouters PF, De Hert SG. Influence of variations in systemic blood flow and pressure on cerebral and systemic oxygen saturation in cardiopulmonary bypass patients. Br J Anaesth. 2013;111:619-26.

28. Lingehall HC, Smulter NS, Lindahl E, Lindkvist M, Engström KG, Gustafson $Y G$, et al. Preoperative cognitive performance and postoperative delirium are independently associated with future dementia in older people who have undergone cardiac surgery: a longitudinal cohort study. Crit Care Med. 2017:45:1295-303

29. Peisker T, Bartoš A, Skoda O, Ibrahim I, Kalvach P. Impact of aging on cerebral vasoregulation and parenchymal integrity. J Neurol Sci. 2010;299:112-5.

30. Leenders KL, Perani D, Lammertsma AA, Heather JD, Buckingham P, Healy MJ, et al. Cerebral blood flow, blood volume and oxygen utilization. Normal values and effect of age. Brain J Neurol. 1990;113(Pt 1):27-47.

31. Caldas JR, Haunton VJ, Panerai RB, Hajjar LA, Robinson TG. Cerebral autoregulation in cardiopulmonary bypass surgery: a systematic review. Interact Cardiovasc Thorac Surg. 2018;26:494-503.

32. Trivedi UH, Patel RL, Turtle MR, Venn GE, Chambers DJ. Relative changes in cerebral blood flow during cardiac operations using xenon-133 clearance versus transcranial Doppler sonography. Ann Thorac Surg. 1997;63:167-74.

33. Kirkham FJ, Padayachee TS, Parsons S, Seargeant LS, House FR, Gosling RG. Transcranial measurement of blood velocities in the basal cerebral arteries using pulsed Doppler ultrasound: velocity as an index of flow. Ultrasound Med Biol. 1986;12:15-21.

34. Kochs E, Hoffman WE, Werner C, Albrecht RF, Schulte am Esch J. Cerebral blood flow velocity in relation to cerebral blood flow, cerebral metabolic rate for oxygen, and electroencephalogram analysis during isoflurane anesthesia in dogs. Anesth Analg. 1993;76:1222-6.

35. Chow G, Roberts IG, Edwards AD, Lloyd-Thomas A, Wade A, Elliott MJ, et al. The relation between pump flow rate and pulsatility on cerebral hemodynamics during pediatric cardiopulmonary bypass. J Thorac Cardiovasc Surg. 1997:114:568-77.

36. Thomas DJ, Marshall J, Russell RW, Wetherley-Mein G, du Boulay GH, Pearson TC, et al. Effect of haematocrit on cerebral blood-flow in man. Lancet Lond Engl. 1977;2:941-3.

37. Gruber EM, Jonas RA, Newburger JW, Zurakowski D, Hansen DD, Laussen $P C$. The effect of hematocrit on cerebral blood flow velocity in neonates and infants undergoing deep hypothermic cardiopulmonary bypass. Anesth Analg. 1999;89:322.

38. Paut $\mathrm{O}$, Bissonnette $\mathrm{B}$. Effects of temperature and haematocrit on the relationships between blood flow velocity and blood flow in a vessel of fixed diameter. Br J Anaesth. 2002;88:277-9.

39. Thiel A, Russ W, Kaps M, Stertmann WA, Hempelmann G. Transcranial Doppler sonography during pulsatile and non-pulsatile extracorporeal circulation. Anaesthesist. 1990:39:226-30.

40. Ševerdija EE, Vranken NPA, Simons AP, Gommer ED, Heijmans JH, Maessen $J G$, et al. Hemodilution combined with hypercapnia impairs cerebral autoregulation during Normothermic cardiopulmonary bypass. Cardiothorac Vasc Anesth. 2015;29:1194-9.

41. Ringaitienè D, Gineitytė D, Vicka V, Žvirblis T, Šipylaite J, Irnius A, et al. Impact of malnutrition on postoperative delirium development after on pump coronary artery bypass grafting. J Cardiothorac Surg. 2015;10:74.

Ready to submit your research? Choose BMC and benefit from:

- fast, convenient online submission

- thorough peer review by experienced researchers in your field

- rapid publication on acceptance

- support for research data, including large and complex data types

- gold Open Access which fosters wider collaboration and increased citations

- maximum visibility for your research: over $100 \mathrm{M}$ website views per year

At $\mathrm{BMC}$, research is always in progress.

Learn more biomedcentral.com/submissions 